\title{
Understanding Diversity - The Impact of Personality on Technology Acceptance
}

\author{
Kay Behrenbruch ${ }^{1}$, Matthias Söllner ${ }^{2}$, Jan Marco Leimeister ${ }^{2}$, and Ludger Schmidt ${ }^{1}$ \\ ${ }^{1}$ Kassel University, Human-Machine Systems Engineering, \\ Mönchebergstr. 7, 34125 Kassel, Germany \\ ${ }^{2}$ Kassel University, Information Systems, Pfannkuchstr. 1, 34121 Kassel, Germany \\ $\{$ K. Behrenbruch, Soellner, Leimeister, L.Schmidt $\} @$ uni-kassel.de
}

\begin{abstract}
Technology is becoming increasingly automated, aiming to ease the life of its users. However, besides the advantages of this trend, users are also faced with increasing risks, e.g., regarding their privacy. Examples are seamless online payments that come with the requirement to provide sensitive, e.g., credit card information, or social networks trying to elicit private information for its users. Research on technology acceptance identified two important factors for the individual decision to accept such kinds of risk: trust and personality traits. In this paper we present a model that integrates research findings for personality traits and for trust in the context of technology acceptance. We show that specific personality traits have a distinct direct or moderating effect. We, e.g., found that two personality traits moderate the relationship between perceived ease of use and intention to use. This moderation could explain the inconsistent findings on this relationship in prior research.
\end{abstract}

Keywords: Technology acceptance, personality traits, trust.

\section{Introduction}

On the one hand, many people publish and discuss detailed data of their lives on internet platforms like "quantifiedself.com", and millions of people share their daily activity in online social networks. On the other hand there are others who feel uncomfortable with using their smartphones, because they want to protect data concerning their movement profile. Again others avoid e-commerce or e-banking to protect sensitive data. Some people are trying many new apps on their smartphones that seem in some way useful to them. Many others avoid new technology because they fear not to be able to operate it or even to damage it. Summing up, there is a great diversity in reactions to new technology in terms of acceptance. For the developers of new technology it is of high interest to understand those differences to be able to address them in their design. Ideally research should provide reliable information on the topic in the form of types of users with different characteristics that are matched with concrete needs for specific design features. The base of such an approach is to build a user model that combines characteristics of the potential users with their tendency to accept or reject new technology. This model needs to be scrutinised and checked to 
provide trustworthy information and to avoid undue stigmatisation of the users. The presented work contributes to improve and extend models that consider the influence of personality on acceptance.

In the beginning, research on technology acceptance concentrated on new occupational software in organizations and institutions [1]. Research presented in this paper focuses on web-enabled software in private use, with private data being processed and stored. In our paper, we focus on the influence of personality traits on technology acceptance. Many new products are not only unfamiliar or evoke resistance just because things are different than before. Furthermore, there is an increasing risk to lose privacy or money. That is why we pick up approaches that integrate trust in models for technology acceptance [2].

After presenting related work we develop hypotheses and a research model for the influence of personality traits on technology acceptance. We present results on basis of an empirical study with a social software that is open for integrating adaptive services for smartphones and discuss those results.

\section{Related Work}

The effect of personality on technology acceptance has been demonstrated by various authors. Especially, the use of social networks has been a major focus of research [3]. Another field of attention has been personality in acceptance of E-commerce [4]. Many aspects of personality were considered in HCI-research such as the need for recognition and sociability [5], computer anxiety, innovativeness, computer selfefficacy, and resistance to change [6], [7], as well as interest in the application domain [8]. The most used characterization of personality in this context is the five factor model FFM [9]. FFM encompasses five personality traits: extraversion, agreeableness, conscientiousness, openness to new experience, and emotional stability [10].

The most used and tested model for technology acceptance is the technology acceptance model TAM [1]. Within this model two beliefs have causal effects on the intention to use technology: perceived ease of use (PEOU) and perceived usefulness (PU). For the case of applications that put their users to some kind of financial or privacy risk, Gefen et al. [2] expanded TAM by another belief that affects the intention to use, namely trust.

\section{Model Development}

Devaraj et al. [9] developed and tested a research model that integrates TAM with personality traits for collaborative technology. This model incorporates FFM and computer self-efficacy. In this paper we adapt and extend this approach for a new class of technology: web-enabled software in private use, with private data being processed and stored. We integrate trust as an important believe influencing intention to use in accordance with authors [2]. Also we integrate the renowned concept of computer anxiety [11] as an additional personality trait. The relationship of the two concepts computer self-efficacy and computer anxiety is controversial in the literature. 
Some authors argue for causal influence of computer anxiety on computer self-efficacy [12] others the other way round [13]. Our research model concentrates on the causal relationships between the three believes trust, PEOU and PU with intention to use and abstracts from the interdependency of the three beliefs specified in prior literature [1], [2], [9]. Some authors discuss a direct influence of personality traits on Intention to use [14], [15]. In accordance with the theory of reasoned action [16], that was used in the development of TAM, we hypothesize an influence of personality traits on the beliefs that determine the intention to use. Corresponding to our argumentation we hypothesize direct influence of personality on the beliefs or moderating effect on the causal relationship between beliefs and intention to use. Concerning trust it has to be kept in mind, that our research model is not addressing the influence of personality traits on trust in general, but on trust in a special kind of technology.

\subsection{Hypothesis and Research Model}

Below we develop hypotheses and a structural model. We did not find equally strong and plausible arguments for an influence of conscientiousness and agreeableness on the integrated beliefs as for the other three concepts of FFM. For example Svendsen et al. [8] do not integrate agreeableness in their model and restrict the hypothesized influence of conscientiousness on acceptance to a subset of the user group. Thus, we did not integrate conscientiousness and agreeableness into our research model.

Emotional Stability. A person who is emotionally stable would remain calm in many situations and would feel secure even when risks occur. An emotionally instable person shows the tendency to experience vulnerability. Feeling secure supports trust while feeling vulnerable makes it much more difficult to bring oneself to build up trust. Zhou and $\mathrm{Lu} \mathrm{[4]} \mathrm{argue} \mathrm{that} \mathrm{a} \mathrm{person} \mathrm{with} \mathrm{low} \mathrm{emotional} \mathrm{stability} \mathrm{feels} \mathrm{a} \mathrm{lack} \mathrm{of}$ control and will not readily build trust in e-commerce.

\section{H1. Emotional Stability will be positively associated with trust.}

Extraversion. The surgency of extraverted people supports a trusting attitude because there is a lot of energy and readiness to overcome doubts and use technology for social interaction. Persons with low extraversion show the tendency to be more reserved and bringing about little motivation for building up trust for new technology and to open up ways for new kinds of social interaction. Zhou and Lu [4] argue that mobile services are a possibility for extroverted people to communicate with their friends at anytime from anywhere. Thus they will more readily give trust.

\section{H2. Extraversion will be positively associated with trust.}

Innovative software, especially on smartphones, has a high potential to foster social interaction. Extroverted people who are talkative and keen on social interaction with others will see much more benefit and use in getting in touch with such kind of technology than introverted ones who are happy with being on their own. Rosen and Kluemper [17] are in line with this argumentation: "Social networking sites would be another way for extroverts to assert themselves and thus could be considered quite useful (p. 4)." 


\section{H3. Extraversion will be positively associated with PU.}

Openness. Interest in novelty fosters the willingness to build up in intention to use new technology on bases of a certain level of PU. People who prefer familiarity over novelty will possibly reject to use the technology with the same level of PU. "People who exhibit this personality trait [openness] seek out new opportunities to exhibit their creativity, and social networking websites are one way to do so. Also since these individuals are more intellectually curious than their peers, a novel way to communicate with friends and associates should be appealing to these people (p. 4)." [17].

H4. Openness will moderate the relationship between PU and intention to use such that the relationship is stronger for individuals with higher openness.

Closed people prefer the simple, plain and straightforward things. Using new technology is not easy right from the start. With lacking interest in the variety of new software a certain level of PEOU won't be enough to build up an intention to use the technology. Open people like to spend time reflecting on things, they enjoy unusual interaction and are willing to overcome some possible challenges by learning when using new technology. Svendsen et al. [8] argue for a positive relation of openness to PEOU: "Openness to experience is an obvious candidate as this personality trait characterises an individual's approach to new situations (p. 5)."

H5. Openness will moderate the relationship between PEOU and intention to use such that the relationship is stronger for individuals with higher openness.

Computer Self-efficacy. People who are confident in interacting with computers and information technology are in a better position to get along with a low level of trust concerning new applications. They probably will feel the ability to compensate the perceived lack of safety. When people have doubts about their capability to use such systems a small risk will probably prevent them from building up on the intention to use this system.

H6. Computer self-efficacy will moderate the relationship between trust and intention to use such that the relationship is stronger for individuals with higher Computer self-efficacy.

Furthermore, related research findings show that users anchor their perception of ease of use to computer self-efficacy [18]. Computer self-efficacy has a major impact on an individual's expectations towards using computers. Contrary to Venkatesh and Bala [18] we do not expect computer self-efficacy to influence PEOU directly, but to moderate the effect of PEOU on intention to use. The belief that one will be able to perform a task with the system in question will alter the willingness to use a system at a given level of PEOU in the first place. From our point of view computer selfefficacy is not a major factor for PEOU. The reason for this is that individuals with high computer self-efficacy will feel to be able to deal with expected problems rather than expecting not to have problems at all.

H7. Computer self-efficacy will moderate the relationship between PEOU and intention to use such that the relationship is stronger for individuals with higher computer self-efficacy. 
Computer Anxiety. The anxiety about the implications of computer use such as the loss of important data or fear of other possible mistakes, like damaging something prevent people from deciding to use a technology [11]. This factor is important for the level of the PEOU. With software that seems very easy, there may be a chance to overcome computer anxiety. When things seem very complicated the probability of rejection is very high. People with a low computer anxiety should be much more likely to build up an intention to use with different levels of PEOU. Nov and Ye [7] postulate that computer anxiety will be negatively related to PEOU of a digital library. The authors do not bring forward arguments for this notion. We prefer to hypothesize a moderating effect, because we claim that the perception of the usability of the system is not altered by anxiety: It is the assessment of the PEOU in comparison to fears of doing something wrong that is the expectable effect.

H8. Computer anxiety will moderate the relationship between PEOU and intention to use such that the relationship is stronger for individuals with lower computer anxiety.

To some people interacting with software is a threat. They fear to do something wrong. The higher perceived risk of something bad to happen will diminish the tendency to trust the software.

H9. Computer anxiety will be negatively associated with trust.

\section{$4 \quad$ Methodology}

We used a laboratory experiment with 344 undergraduate business students. The participants used a mobile application that was developed within a multi-disciplinary research project and supports mobile social networks, group interaction and mobility. It was designed for the group of 20- to 35-year-olds. The application supports its users in organizing meetings with friends at events. Events can be public or private happenings like concerts or parties. The application helps to plan the event, navigate the user to the event, and supports the user at the event itself. It proposes events to the users that fit their individual interests as well as their personal calendars. The application suggests means of transport and informs about possible delays, e.g. when using public transport. At the event, information concerning the location, the program, and tickets can be retrieved from other services that can be integrated. If desired by the user the application is able to suggest new friends based on the user's settings and interests. Within the laboratory experiment, the students received information on the idea of the system, how it works, and how to interact with the application. Afterwards, all students were asked to complete four predefined tasks using the mobile application, ensuring that participants recognized all functionalities of the system. Then all participants were asked to fill out a questionnaire, including items for FFM [19], Computer Anxiety [11], Computer Self-Efficacy [13], Trust [22], PEOU and PU [20]. Responses were recorded on a bipolar 9-point Likert response format. To achieve high quality results, we implemented several reverse coded items into the questionnaire, and checked all cases regarding the consistence of the answers given to the items relevant for our data analysis and the reverse coded control items. Furthermore, 
we dropped all cases that included missing data to ensure high data quality. In the end, 272 data sets were included in our analysis. We relied on SPSS 20 and SmartPLS 2.0 [23] to analyse our data. We used the approach of Chin [24] to model and evaluate the moderating effects in PLS.

\section{$5 \quad$ Results}

Before discussing the results regarding our hypotheses, we first need to assess the quality of our reflective measurement models. Consequently, we check the average variance extracted (AVE), the composite reliability, the indicator loadings, crossloadings and correlations among our constructs as quality criteria [24]. Summing up, all values were above the required quality criteria. The lowest AVE was observed for PEOU $(0.7640>0.5)$. The lowest composite reliability was observed for trust $(0.9266$ $>0.6$ ) and the lowest indicator loading was 0.868 (>0.7). Regarding the crossloadings, all indicators showed the highest loading on their desired construct and the AVE for each construct was higher than any correlation with another construct. Consequently, our measurement models are reflective and reliable, and we thus can now confidently turn towards the evaluation of our hypotheses.

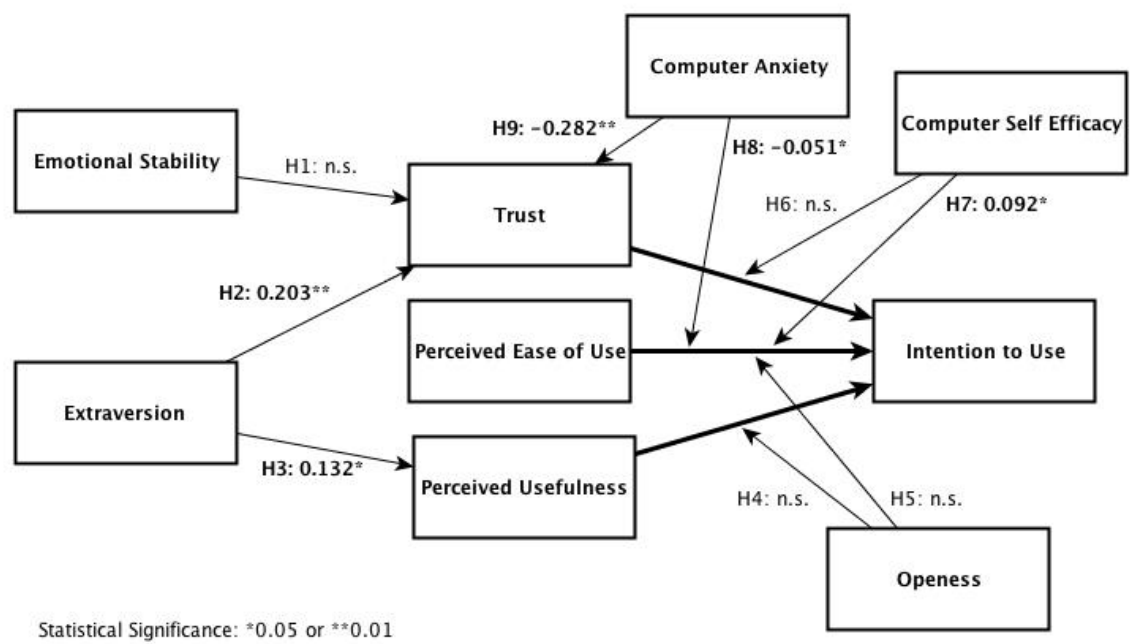

Fig. 1. Research model with results for hypotheses $\mathrm{H} 1$ to $\mathrm{H} 9$

Overall, we found support for five of our nine hypotheses. We could show that there is a significant impact of extraversion on trust $(\mathrm{H} 2$, path coefficient $0.203, \mathrm{p}<$ $0.01)$ and PU $(\mathrm{H} 3,0.132, \mathrm{p}<0.05)$. Furthermore, we could show that there is a significant negative impact of computer anxiety on trust $(\mathrm{H} 9,-0.282, \mathrm{p}<0.001)$. Additionally, we could show a negative moderation effect between computer anxiety and PEOU (H8, -0.051, p < 0.05) and a positive effect between computer self-efficacy and PEOU (H7, 0.092, $\mathrm{p}<0.05)$. We could not find a significant impact of emotional 
stability on trust (H1, -0.075 , not significant). Furthermore, we did not find empirical support for three of our supposed moderation effects. In particular the moderation effects between openness and PEOU (H4, 0.002, n.s.), between openness and PU (H5, -0.002 , n.s.), and between computer self-efficacy and trust (H6, -0.010, n.s.). A graphical illustration of the results regarding our hypotheses is presented in Fig. 1.

\section{Discussion}

With respect to the general personality traits of FFM our results support the elevated position of extraversion with respect to technology acceptance. Both hypotheses for extraversion could be validated in our study.

Concerning the technology related item computer anxiety we found a new and significant relationship with trust (H9). The approved moderating effect of computer anxiety and computer self-efficacy on the causal relationship of PEOU and intention to use (H7 and H8) contradicts with the formation of hypotheses and the findings of Venkatesh and Bala [18]. In accordance with Venkatesh and Bala [18] we did not expect an influence of the two technology related items on PU. Our findings concerning PEOU can contribute to another current research topic: Gefen and Straub [21] ask for the reason of the changing importance of PEOU for intention to use in different studies and state that this varying importance of PEOU may be related to the nature of the task. Derived from our research results also the user group might be important with respect to the expression of characteristics for computer anxiety and computer self-efficacy. Our ongoing research will focus on verifying our findings for diverse user groups. The findings concerning relationship of PEOU and personality traits $(\mathrm{H} 7$, H8) needs to be attuned and further developed with respect to other research findings [18], [21]. In this context the following concepts will be also considered: personal innovativeness [14], computer playfulness and perception of external control [18].

Acknowledgment. We thank Hesse's Ministry of Higher Education, Research, and the Arts for funding our work as part of the research funding program LOEWE.

\section{References}

1. Davis, F.D., Bagozzi, R.P., Warshaw, P.R.: User Acceptance of Computer Technology: A Comparison of Two Theoretical Models. Management Science 35(8), 982-1003 (1989)

2. Gefen, D., Karahanna, E., Straub, D.W.: Trust and TAM in online shopping: an integrated model. MIS Q. 27(1), 51-90 (2003)

3. Amichai-Hamburger, Y., Vinitzky, G.: Social network use and personality. Computers in Human Behavior 26(6), 1289-1295 (2010)

4. Zhou, T., Lu, Y.: The Effects of Personality Traits on User Acceptance of Mobile Commerce. International Journal of Human-Computer Interaction 27(6), 545-561 (2011)

5. Hughes, D.J., Rowe, M., Batey, M., Lee, A.: A tale of two sites: Twitter vs. Facebook and the personality predictors of social media usage. Computers in Human Behavior (December 2011) 
6. Nov, O., Ye, C.: Personality and Technology Acceptance: Personal Innovativeness in IT, Openness and Resistance to Change. In: Proceedings of the 41st Annual Hawaii International Conference on System Sciences, HICSS 2008, p. 448 (2008)

7. Nov, O., Ye, C.: Users' personality and PEOU of digital libraries: The case for resistance to change. Journal of the American Society for Information 59, 845-851 (2008)

8. Svendsen, G.B., Johnsen, J.-A.K., Almås-Sørensen, L., Vitters $\varnothing$, J.: Personality and technology acceptance: the influence of personality factors on the core constructs of the Technology Acceptance Model. Behaviour \& Information Technology, 1-12 (February/March 2011)

9. Devaraj, S., Easley, R.F., Crant, J.M.: How Does Personality Matter? Relating the FiveFactor Model to Technology Acceptance and Use. Information Systems Research 19(1), 93-105 (2008)

10. McAdams, D.P.: Five factor model in personality. Journal of Personality 60(2), 329-361 (1992)

11. Bozionelos, N.: Computer anxiety: relationship with computer experience and prevalence. Computers in Human Behavior 17(2), 213-224 (2001)

12. Bennett, J., Perrewé, P.L.: An Empirical Examination of Individual Traits as Antecedents to Computer Anxiety and Computer Self-Efficacy. Management Information Systems 26(4), 381-396 (2012)

13. Compeau, D.R., Higgins, C.A.: Computer Self-Efficacy: Development of a Measure and Initial Test. MIS Quarterly 19(2), 189-211 (1995)

14. Sim, J.J.: Influence of Personal Innovativeness, Self-efficacy and Subjective Norm in Mcommerce Acceptance?: A Conceptual Review. International Journal of Network and Mobile Technologies 3(3), 40-48 (2012)

15. Amichai-Hamburger, Y.: Internet and personality. Computers in Human Behavior 18(1), 1-10 (2002)

16. Fishbein, M., Ajzen, I.: Belief, Attitude, Intention and Behaviour: An Introduction to Theory and Research. Addison-Wesley (1975)

17. Rosen, P.A., Kluemper, D.H.: The Impact of the Big Five Personality Traits on the Acceptance of Social Networking Website. In: Proceedings of the Fourteenth Americas Conference on Information Systems (2008)

18. Venkatesh, V., Bala, H.: Technology Acceptance Model 3 and a Research Agenda on Interventions. Decision Science 39(2), 273-315 (2008)

19. Gosling, S.D., Rentfrow, P.J., Swann, W.B.: A very brief measure of the Big-Five personality domains. Journal of Research in Personality 37(6), 504-528 (2003)

20. Venkatesh, V., Morris, M.G., Davis, G.B., Davis, F.D.: User Acceptance of Information Technology: Toward a Unified View. Management Information Systems 27(3), 425-478 (2010)

21. Gefen, D., Straub, D.W.: The Relative Importance of PEOU in IS Adoption: A Study of ECommerce Adoption. Journal of the Association for Information Systems 1(1), 8 (2000)

22. Söllner, M., Hoffmann, A., Hoffmann, H., Wacker, A., Leimeister, J.M.: Understanding the Formation of Trust in IT Artifacts. In: Proceedings of the International Conference on Information Systems (ICIS), Orlando, Florida, USA (2012)

23. Ringle, C.M., Wende, S., Will, A.: SmartPLS 2.0. Hamburg (2005)

24. Chin, W.W.: The Partial Least Squares Approach to Structural Equation Modeling. In: Marcoulides, G. (ed.) Modern Methods for Business Research. LEA, London (1998) 